\title{
A EDUCAÇÃO BRASILEIRA E OS AVANÇOS NO PROCESSO DE REGULAMENTAÇÃO DO ENSINO A DISTÂNCIA
}

\author{
FLORIANÓPOLIS/SC JUNHO/2018
}

\author{
Marjorie de Almeida Araújo - FGF- Faculdade da Grande Fortaleza - aacsj@hotmail.com \\ JAMARA CARDOSO NEVES BRAZ - ISERJ - jamarabraz@yahoo.com.br \\ Samia Regina de Carvalho - UNESP - samya_carvalho@hotmail.com \\ William Vinicius Pinto - Universidade Nove de Julho - will_vinicius@hotmail.com \\ Paulo Henrique Lopes Aguiar - Faculdades Oswaldo Cruz (FOC) - paulolopes10@gmail.com \\ Renata M. S. Costa - Guia EaD Brasil (voluntária) - renatamscosta@hotmail.com
}

Tipo: Investigação Científica (IC)

Natureza: Planejamento de Pesquisa

Categoria: Estratégias e Políticas

Setor Educacional: EDUCAÇÃO SUPERIOR

\begin{abstract}
RESUMO
Este artigo busca apresentar para a sociedade como se encontra regulamentada a educação a distância no Brasil, trazendo um levantamento da base legal que a envolve, com o objetivo de demonstrar que esta modalidade de ensino é capaz de colaborar significativamente para o crescimento do país, tendo em vista ser a forma mais eficaz de garantir o exercício do direito à educação de todo cidadão. O presente estudo tem natureza qualitativa, objetivo exploratório e se utilizou da pesquisa bibliográfica, baseando-se em livros, artigos, revistas e leis, materiais estes encontrados em publicações impressas e disponibilizadas por meio eletrônico. Foi realizado um apanhado geral do ponto de vista de diversos estudiosos, dentre eles João Mattar e Frederic M. Litto, chegando-se no final a uma conclusão sob a ótica dos autores deste artigo, onde se optou por uma linguagem clara e de fácil compreensão, restando comprovada a possibilidade de aplicação da EaD nos mais diferentes níveis de aprendizagem, podendo ser aplicada da educação básica ao doutorado, sem que se perca em qualidade de ensino.
\end{abstract}

Palavras-chave: Educação, Direito, Regulamentação, Legislação, EaD, Aplicação, Níveis, Aprendizagem, Qualidade.

\section{AGRADECIMENTOS}

A FERNANDA FURUNO DO GUIA EAD BRASIL E A RENATA COSTA PELA IDEALIZAÇÃO DO PROJETO. A MAJORIE ARAÚJO, MÔNICA CAMPOS E RENATA COSTA PELA SUPERVISÃO E AOS PROFESSORES ESCRITORES. 


\section{1 - INTRODUÇÃO}

O Ensino a distância no Brasil é regido principalmente pelas bases legais que foram estabelecidas na Lei de Diretrizes e Bases da Educação Nacional (LDB) e pelo atual Plano Nacional de Educação de 2014, observando-se, contudo, o que estabelece a Constituição da República Federativa do Brasil de 1988, já que é a norma suprema sob a qual o país se rege. Corroborando com as bases legais em que se alicerçam a educação brasileira, temos diversos pareceres, portarias, decretos e resoluções que visam tentar regulamentar de forma mais completa possível o setor educacional.

A legislação que ampara a Educação a Distância também regulamenta e determina suas ações e funções. Todavia, o grande desafio é fazer com que as instituições de ensino (IE) atendam às exigências pedagógicas, sendo ainda mais complexo garantir a segurança e qualidade em todo o processo educativo realizado nessa modalidade de ensino.

Notório é que as novidades ocorridas em 2017, no que diz respeito à regulamentação da EaD no ensino médio, mestrado e doutorado, ocasionou uma grande repercussão entre professores, alunos e Instituições de ensino. Isso porque, de fato a realidade da educação brasileira tem avançado rapidamente, exigindo assim, rápidas transformações quanto à regulamentação da educação como um todo.

\section{2 - ENSINO A DISTÂNCIA COMO GARANTIA DE EXERCÍ́cIO DO DIREITO A EDUCAÇÃO}

Sabe-se que a educação é um fator de suma importância para o desenvolvimento integral do indivíduo e, consequentemente, a materialização de grandes transformações no contexto histórico-social no qual ele está inserido. Entretanto, o processo educacional necessita ser concretizado de forma equânime, garantindo-se o exercício do direito à educação expresso na Constituição Federal, sem deixar de levar em consideração as singularidades e condições intelectuais de cada grupo de indivíduos. Como perfeitamente definiu José Carlos Libâneo:

Educação compreende o conjunto dos processos, influências, estruturas e ações que intervêm no desenvolvimento humano de indivíduos e grupos na sua relação ativa com o meio natural e social, num determinado contexto de relações entre grupos e classes sociais, visando à formação do ser humano (Libâneo, 2001, p.7).

No Brasil, a história da educação é marcada pela exclusão e meritocracia, refletindo o 
descompasso entre o que preceitua a Constituição do país e a realidade existente, pois "os números de escolarização do Brasil, se comparados ao resto do mundo, dão-nos um retrato da situação calamitosa em que se encontra a educação brasileira" (Volpi, 1997, p. 56)

A Lei de Diretrizes e Bases da Educação Nacional (Lei 9.394/96), conhecida como Lei Darcy Ribeiro, expressamente, no seu artigo $2^{\circ}$, reitera o disposto na Constituição Federativa do Brasil, ressaltando a educação como um direito de todos. Por outro lado, a Comissão Internacional sobre Educação para o Século XXI, coordenada por Jacques Delors, enviou relatório para a UNESCO, destacando que a educação é definida como um valor humano a ser buscado durante toda a vida, devendo ser organizada em torno de quatro pilares fundamentais, qual seja:

[...] aprender a conhecer, isto é adquirir os instrumentos da compreensão; aprender a fazer, para poder agir sobre o meio envolvente; aprender a viver juntos, a fim de participar e cooperar com os outros em todas as atividades humanas; finalmente aprender a ser, via essencial que integra as três precedentes. É claro que estas quatro vias do saber constituem apenas uma, dado que existem entre elas múltiplos pontos de contato, de relacionamento e de permuta. (DELORS, 2003, p.90).

Nesse sentido, constata-se que no Brasil o objetivo de garantir o acesso à educação a todo cidadão, ainda não foi alcançado, objetivo este fundamentado constitucionalmente:

Art. 205. A educação, direito de todos e dever do Estado e da família, será promovida e incentivada com a colaboração da sociedade, visando ao pleno desenvolvimento da pessoa, seu preparo para o exercício da cidadania e sua qualificação para o trabalho (Brasil, 2018).

O Plano Nacional de Educação (PNE) de 2014 descreve de forma coesa as metas a serem alcançadas nos próximos dez anos, fazendo, inclusive, referência a superação do analfabetismo entre jovens com 15 anos ou mais. Nesse contexto, a disseminação da Educação a Distância, sem dúvida alguma, vem de encontro com as expectativas trazidas pelo PNE, uma vez que leva em consideração a possibilidade de diferentes processos educacionais, tornando o espaço de aprendizagem cada vez mais interativo e adaptado à realidade da população, o que consequentemente, contribui para a formação de profissionais que passam a ter em suas mãos meios de superar as condições sociais a eles imposta.

A educação a distância possibilita a materialização de direitos até então só contidos em 
diversos documentos que tratam sobre o tema. Porém, é preciso atentar para que esta educação seja levada a todo cidadão com a mesma qualidade, ou do contrário, se tornará mais um meio de exclusão social. Neste sentido, Demo entende que: "Qualidade, por sua vez, aponta para a dimensão da intensidade. Tem a ver com profundidade, perfeição, principalmente com participação e criação. Está mais para ser do que para ter" (DEMO, 2001, p. 10).

O Plano Nacional de Educação define que uma das prioridades é melhorar a qualidade do ensino em todos os níveis. Para isto, são traçados vinte e três objetivos e metas, estando entre elas o estabelecimento do sistema de credenciamento das instituições e reconhecimento dos cursos superiores, bem como o seu alinhamento com um sistema nacional de avaliação. Este foi um importante passo, na medida em que a avaliação das instituições e cursos foi associada, definitivamente, à qualidade do sistema federal de educação superior. $O$ atual PNE continua a traçar estratégias que favorecem a qualidade, como, por exemplo, o estabelecimento da meta de $75 \%$ de mestres e doutores compondo o corpo docente das instituições de ensino superior, com um mínimo de $35 \%$ de doutores. Os resultados atuais mostram que, apesar de ter se atingido esta meta, apenas as instituições públicas de ensino superior apresentam os melhores resultados.

Uma grande preocupação demonstrada por João Mattar em uma entrevista a determinada instituição de ensino, é com relação à fusão de grandes instituições de ensino que tem ocorrido nos últimos tempos, pois instituições internacionais têm demonstrado interesse financeiro no Brasil, visando obter lucro sobre o sistema educacional, padronizando conteúdos e impedindo o crescimento das instituições brasileiras. Diante dessa realidade, a comunidade acadêmica tem cobrado do governo brasileiro estratégias legais que possam conter e regulamentar o avanço do capital estrangeiro nesse setor, pois se assim não for, a educação que tende a avançar pela disseminação do ensino a distância, poderá retroceder no que diz respeito à qualidade educacional que se almeja.

\section{3 - A EAD FLEXIBILIZANDO A EDUCAÇÃO BÁSICA E O ENSINO MÉDIO}

Dispondo sobre a Educação a distância, a LDB enuncia em seu artigo 80 que: "O Poder Público incentivará o desenvolvimento e a veiculação de programas de ensino a distância, em todos os níveis e modalidades de ensino e educação continuada " (BRASIL, 2018).

O artigo 32 da Lei 9.394/96 em seu parágrafo $4^{\circ}$ fala sobre a possibilidade de ensino 
fundamental na modalidade EaD em situações emergenciais, enquanto que o decreto 9.057/17, em seu artigo 9으, especifica quais seriam as situações emergenciais, caracterizando-se aquelas circunstâncias em que os estudantes :

I - estejam impedidas, por motivo de saúde, de acompanhar o ensino presencial; II - se encontrem no exterior, por qualquer motivo; III - vivam em localidades que não possuam rede regular de atendimento escolar presencial;IV - sejam transferidas compulsoriamente para regiões de difícil acesso, incluídas as missões localizadas em regiões de fronteira;ou $\mathrm{V}$ - estejam em situação de privação de liberdade (BRASIL, 2018).

Em se tratando da oferta do Ensino Médio é necessário destacarmos a Medida Provisória 746/2016, mais conhecida como "MP do Ensino Médio", que foi convertida em 2017 na lei 13.415, a qual oportuniza ao aluno a flexibilização curricular.

A lei supracitada visa substituir o modelo único por outro diversificado e flexível, alterando a LDB e estabelecendo em seu artigo 36, que:

O currículo do ensino médio será composto pela Base Nacional Comum Curricular e por itinerários formativos, que deverão ser organizados por meio da oferta de diferentes arranjos curriculares, conforme a relevância para o contexto local e a possibilidade dos sistemas de ensino, a saber: I - linguagens e suas tecnologias; II - matemática e suas tecnologias; III - ciências da natureza e suas tecnologias; IV - ciências humanas e sociais aplicadas; $V$ - formação técnica e profissional (BRASIL, 2018).

A referida lei no art. $24 \S 1^{\circ}$ também amplia a carga horária do ensino médio, de forma progressiva, para mil e quatrocentas horas. Esse aumento da carga horária visa cumprir a meta de número 6 do PNE, a qual prevê a educação em tempo integral em ao menos $50 \%$ das escolas públicas, atendendo a um mínimo de $25 \%$ de alunos da educação básica.

Ainda no $\S 11^{\circ}$ do artigo 36 , está expresso que se garantido o cumprimento das exigências curriculares, os sistemas de ensino poderão reconhecer competências e firmar convênios com instituições de educação a distância com notório reconhecimento mediante as seguintes comprovações:

I - demonstração prática; II - experiência de trabalho supervisionado ou outra experiência adquirida fora do ambiente escolar; III - atividades de educação técnica oferecidas em outras instituições de ensino credenciadas; IV - cursos oferecidos por 
centros ou programas ocupacionais; $V$ - estudos realizados em instituições de ensino nacionais ou estrangeiras; VI - cursos realizados por meio de educação a distância ou educação presencial mediada por tecnologia (BRASIL, 2018).

A resolução nํ 1 de 2016 do CNE/CEB, se refere em seu artigo $4^{\circ}$ sobre as instituições públicas de ensino vinculadas aos sistemas estaduais, as quais devem se orientar pelas seguintes Diretrizes Operacionais:

I - A oferta de Ensino Médio, de Educação Profissional Técnica de Nível Médio e de Educação de Jovens e Adultos (EJA), nas etapas de Ensino Fundamental e de Ensino Médio, na modalidade de Educação a Distância (EAD), se dará, prioritariamente, no âmbito do próprio sistema estadual de ensino, nos seguintes termos: a) atenderá ao disposto nas normas definidas pelo respectivo Conselho Estadual de Educação;b) o credenciamento original da instituição de ensino para atuar na modalidade de Educação a Distância (EAD) e a autorização de funcionamento de cursos e programas serão concedidos pelo Conselho Estadual de Educação e terão validade para atuar apenas na sua Unidade da Federação (BRASIL, 2018).

Já o decreto 9.057 de maio de 2017, em seu artigo 8º, dispõe sobre a oferta do ensino médio, mantendo os termos do $\S 11$ do art. 36 da Lei $n^{\circ} 9.394$, ou seja, compete às autoridades dos sistemas de ensino estadual, municipal e distrital, no âmbito da unidade federativa, autorizar os cursos e o funcionamento de instituições de educação na modalidade a distância.

\section{4 - A EDUCAÇÃO A DISTÂNCIA NOS CURSOS DE MESTRADO E DOUTORADO}

As principais mudanças ocorridas na Legislação da EaD, por meio de Resoluções, Portarias e Pareceres do CES-CNE, especialmente no que se relaciona a implementação dos cursos de Mestrado e Doutorado, inaugura um novo conceito de Pós Graduação stricto sensu, definindo os programas, os sistemas de avaliações das propostas de novos cursos, os processos de autorização, bem como os credenciamentos e reconhecimentos de cursos em forma associativa .

Os novos regimentos surgem para construção de uma nova fase no que se refere a essa modalidade de ensino, iniciando-se pela Portaria Normativa 389 de 23/03/2017 do MEC, que preconiza os objetivos da Pós Graduação stricto sensu como uma forma indispensável para o estreitamento das relações entre as universidades e o setor produtivo com o devido comprometimento no processo de formação profissional. Para impulsionar o desenvolvimento da EaD, a publicação do Decreto 9.057/2017 dispõe o 
seguinte conceito para educação a distância:

Art, 1: Para os fins deste Decreto, considera-se educação a distância a modalidade educacional na qual a mediação didático-pedagógica nos processos de ensino e aprendizagem ocorra com a utilização de meios e tecnologias de informação e comunicação, com pessoal qualificado, com políticas de acesso, com acompanhamento e avaliação compatíveis, entre outros, e desenvolva atividades educativas por estudantes e profissionais da educação que estejam em lugares e tempos diversos" (BRASIL, 2018).

Segundo essa linha conceitual, ficou estabelecido no artigo 18, do mesmo decreto, a perspectiva da oferta de programas de mestrado e doutorado condicionados a recomendação e fiscalização da Coordenação de Aperfeiçoamento de Pessoal de Nível Superior - Capes.

No mesmo ano, novas diretrizes foram fixadas para a implantação da Pós Graduação Stricto Sensu na EAD, sendo publicadas as Portarias Normativas 389 , 131 e 214 da CAPES (Coordenação de Aperfeiçoamento de Pessoal de Nível Superior). De modo efetivo, uma nova trajetória para o Ensino a Distância se completa com a publicação da Resolução ํo 07 e do Parecer 462 do CNE/CES.

Registre-se que a Portaria Normativa 131 de 2017 em seu $\S 1^{\circ}$ do artigo 1, trata das orientações específicas para a elaboração das propostas de novos cursos, regulamenta a forma como serão submetidas essas propostas na modalidade profissional, estabelecendo, ainda, que ficarão vinculadas a portarias e regulamentos próprios.

No que se refere à Portaria Normativa 214 de 2017, esta consagra regras inéditas para programas de mestrado e doutorado na forma associativa, que deverão atuar de modo articulado e oficializado com responsabilidades definidas e compartilhadas entre as associadas. Nota-se aqui uma abertura internacional para a produção científica, ao se verificar os objetivos das formas associativas que estão definidos no Parecer 462/2017 do CNE/CES, em seu Capítulo III :

Art. 9 Os cursos de pós-graduação stricto sensu regulares poderão ser oferecidos em formas associativas ou interinstitucionais. $\S 2^{\circ}$ A associação poderá ocorrer com a presença de instituições estrangeiras, justificada pela qualidade, agregação de conhecimento e de competência ao programa associado (BRASIL, 2018).

A resolução 07/2017 do CNE/CES, no seu artigo 1ํㅡㄹ enumera critérios para os 
programas institucionais de pós graduação stricto sensu, como se depreende do $\S 1^{\circ}$ ํ. deste regimento, onde estão expostos os objetivos dos cursos de mestrado e doutorado, quais sejam: " desenvolvimento da produção intelectual comprometida com o avanço do conhecimento e de suas interfaces com o bem econômico, a cultura, a inclusão social e o bem estar da sociedade"(BRASIL, 2018).

Por fim, convém pontuar a regra excepcional disposta no artigo 10 do Parecer 462/2017, nas Disposições Transitórias, que admite a aquisição do título de Doutor mediante a defesa direta da tese, cabendo a CAPES a fiscalização, conforme o artigo $4^{\circ}$ do mesmo documento.

\section{CONSIDERAÇÕES FINAIS}

As transformações sociais, pedagógicas e econômicas tem levado a evolução da educação a distância, a qual tem passado por constantes transformações em sua legislação, influenciando cada dia mais na melhoria de vida da população através do conhecimento e formação, colaborando, assim, para o crescimento da sociedade como um todo.

Percebe-se, por este artigo, que o conhecimento da legislação que rege a educação a distância é essencial à sua aplicabilidade, ficando claro que o rápido avanço na regulamentação desta modalidade de ensino tem ocorrido devido ao fato de estar se desmistificando o conceito de Educação, ficando com o passar dos anos ainda mais notória a eficiência que a EaD possui na construção do conhecimento e na formação profissional.

Ainda existe algum preconceito com a educação a distância, por parte da população e da própria comunidade acadêmica, todavia, ao passo que a regulamentação avança e o ensino vai sendo disseminado por todas as classes sociais, essa postura vai sendo modificada. A esse respeito Frederic M. Litto se manifesta dizendo que:

Aprendi, em muitos anos de pesquisa, duas "regras não escritas" sobre como avaliar evidências: "não dá para brigar contra os fatos"; e "quando você não consegue arguir contra os fatos, ata que o questionador". A primeira frase me deixa tranquilo sobre a eficácia e o sucesso futuro da aprendizagem a distância; a segunda me deixa à espreita, aguardando os ataques ad hominem que conservadores, sem fatos para comprovar suas afirmações, insistem em lançar na direção do futuro e sua consequente tecnologia, que será tão meritória quanto mais democrática for a aprendizagem a ela subordinada. (As interfaces da Ead na educação brasileira, Frederic M. Litto, REVISTA USP • São 
PAULO n. 100, p. 65)

Neste contexto, concordamos com Frederic Litto e acreditamos que os avanços da legislação corroboram para que a EaD conquiste uma real e permanente credibilidade, continuando a avançar e beneficiando de forma quantitativa e qualitativa 0 desenvolvimento da educação brasileira.

\section{REFERÊNCIAS}

BRASIL. Constituição (1988). Constituição da República Federativa do Brasil. Brasília, DF: Senado Federal: Centro Gráfico, 1988. 292 p. Acesso em: 16 de abr. 2018.

BRASIL. Decreto o 9.057, de 25 de maio de 2017. Disponível em: Acesso em: $13 / 03 / 2018$

BRASIL. Lei 13.415, 16 de Fevereiro de 2017. Conversão da Medida Provisória no 746, de 2016. Disponível em: Acesso: 29/04/2018

BRASIL. Lei de Diretrizes e Bases da Educação Nacional (LDB). Lei no 9.394/96, de 20 de dezembro de 1996. Disponível em: Acesso em: 12/04/2018

BRASIL. Resolução no 1, 2 de fevereiro de 2016. Diretrizes Operacionais Nacionais para o credenciamento institucional e oferta de cursos e programas de Ensino Médio, Educação Profissional Técnica de Nível Médio, Educação de Jovens e Adultos, do Ensino Fundamental e do Ensino Médio, na modalidade Educação a Distância, em regime de colaboração entre os sistemas de ensino. Brasília, Disponível em: Acesso $10 / 03 / 2018$

BRASIL. Observatório PNE. (Ed.). Ensino Médio. Disponível em: . Acesso em: 10 abr. 2018.

BRASIL, Ministério da Educação (Ed.) Plano Nacional de Educação. Disponível em:< pne.mec.gov.br>. Acesso em: 12 de abr. 2018.

BRASIL, Ministério da Educação. Resolução 462 CNE/CES. Disponível em: Acesso em: 20 de abr. 2018. 
BRASIL, ABMES. Resolução 07/2017 CNE/CES. Disponível em: <

https://abmes.org.br/legislacoes/detalhe/2287/resolucao-ces-cne-n-7> Acesso em: 24 de abr. 2018.

DELORS, J. et al. Educação: um tesouro a descobrir. Relatório para a Unesco da Comissão Internacional sobre Educação para o século XXI. 2. ed. São Paulo: Cortez; Brasília: MEC/Unesco, 2003.

DEMO, P. Educação e qualidade. 6ª . ed. São Paulo: Papirus, 2001;

LIBÂNEO, José Carlos. Pedagogia e pedagogos: inquietações e buscas. Educar, 17, 153-176, 2011.

LITTO, F. M. As interfaces da EAD na educação brasileira. Revista USP, n. 100, p. 57-66, 2014.

MATTAR, J. UNICESUMAR (Ed.) Tendências e Novas Tecnologias na EAD 2014. Disponível em: . Acesso: 23/04/2018.

VOLPI, Mario. O adolescente e o ato infracional. Cortez Editora, 1997. 